\title{
Antibiotics Prophylaxis in Patients with CAKUT, Does It Actually Prevent UTI? A Single Center Experience at South Africa
}

\author{
Nneka Chioma Okoronkwo ${ }^{*}$, Abdullahi Mudi², Cecil Levy ${ }^{3}$, Thuli Khumalo ${ }^{3}$, G. Moonsamy ${ }^{3}$ \\ ${ }^{1}$ Department of Paediatrics, Abia State University, Uturu, Nigeria \\ ${ }^{2}$ Department of Paediatrics, Bayero University, Kano State, Nigeria \\ ${ }^{3}$ Division of Paediatric Nephrology, Charlotte Maxeke Johannesburg Academic Hospital, South Africa \\ Email: ${ }^{*}$ nnekaceo@rocketmail.com
}

How to cite this paper: Okoronkwo, N.C., Mudi, A., Levy, C., Khumalo, T. and Moonsamy, G. (2018) Antibiotics Prophylaxis in Patients with CAKUT, Does It Actually Prevent UTI? A Single Center Experience at South Africa. Open Journal of Nephrology, 8, 94-104.

https://doi.org/10.4236/ojneph.2018.84011

Received: September 30, 2018

Accepted: November 25, 2018

Published: November 28, 2018

Copyright $\odot 2018$ by authors and Scientific Research Publishing Inc. This work is licensed under the Creative Commons Attribution International License (CC BY 4.0).

http://creativecommons.org/licenses/by/4.0/

CC) (i) Open Access

\begin{abstract}
Background: Congenital anomalies of the kidney and urinary tract (CAKUT) are a well-documented risk factor for the development of urinary tract infection (UTI) in children. Prevention of UTI in this group of patients is advocated due to their increased risk of renal scarring, hypertension and end stage kidney failure. Methods: A 10-year retrospective review of CAKUT patients at the Johannesburg Academic Hospital, who were placed on prophylactic antibiotics over a certain period was done. The rate of UTI, the types of causative organisms isolated and the efficacy of prophylactic antibiotics in preventing UTI were documented. Results: Thirty-six (36) out of 134 patients had been started on prophylactic antibiotics after the diagnosis of CAKUT was made. There was a statistically significant association between the use of prophylactic antibiotics and the rate of UTI $(\mathrm{p}<0.001)$. Patients who were not on a prophylactic antibiotic were five times more likely to have a UTI than those who were on a prophylactic antibiotic $(\mathrm{OR}=5.21, \mathrm{P}=0.001,95 \%$ CI: 1.9906 - 13.6277). There was a statistically significant association between the type of bacteria isolated and the use of antibiotic prophylaxis $(\mathrm{p}=0.031)$. Conclusion: Antibiotic prophylaxis was very effective in decreasing the rate of UTI in our cohort of patients with CAKUT.
\end{abstract}

\section{Keywords}

Antibiotic Prophylaxis, Children, CAKUT, UTI, South Africa

\section{Introduction}

The presence of micro-organisms in the urinary tract, with clinical signs and symptoms (Urinary Tract Infection) [1], is commoner in children with Conge- 
nital anomalies of the kidney and urinary tract (CAKUT) than in the general paediatric population [2] [3] [4]. Among other mechanisms, CAKUT alters the natural free unidirectional flow of urine causing stasis and thereby enhancing the growth of pathogenic micro-organisms [5] [6].

The incidence of CAKUT among patients with urinary tract infection (UTI) ranges from $25 \%$ - 55\% [6]. Ring and Zobel found CAKUT in $42 \%$ of infants with UTI, with obstructive uropathy and vesicoureteral reflux (VUR) accounting for $37 \%$ and $59 \%$ of all the anomalies respectively [7]. Also, in that study $61 \%$ of infants with CAKUT had UTI [7].

Recurrent UTI as a result of CAKUT may predispose children to renal scarring, hypertension and CKD, which carries the risk of progression to ESRD requiring renal replacement therapy [2] [8] [9] [10].

Prevention of UTI in this group of patients is advocated due to their increased risk of renal scarring, hypertension and end stage kidney failure [2] [8] [9] [10].

In addition to enhancing personal hygiene and prevention of constipation, some clinicians place a selected group of CAKUT patients onto continuous antibiotic prophylaxis. Indications for continuous antibiotic prophylaxis include children less than 5 years with VUR, or other structural anomalies, and those who have had three documented UTIs in one year [2] [8] [9] [11].

The use of antimicrobial prophylaxis in patients with CAKUT and recurrent UTI is still controversial [10] [12] [13] [14]. Those opposing the use of prophylactic antibiotics voice the concern that this practice may breed resistant strains of pathogens, increase the risk of breakthrough infections, and encourage adverse drug reactions. They also argue that the effectiveness of antibiotic prophylaxis is questionable, and that many patients will need to be treated to benefit one child. Finally, they fear that any benefiting from this practice may be interrupted by low adherence of patients to the prescribed medication [10] [12] [13] [14].

All the aforementioned concerns are due to the fact that previous studies on the use of prophylactic antibiotics were rife with contradictory results and divergent conclusions. However, some well controlled and randomized studies, including the RIVUR and PREVENT trials, have documented some benefits of antibiotic prophylaxis use in select groups of patients [8] [13] [15] [16].

Although prophylactic antibiotics have been recommended for children with grades IV and V VUR and other significant urological anomalies, the current recommendation is to discourage prophylactic antibiotic use in children with recurrent UTI who do not have CAKUT. Rather, they should be treated promptly and adequately whenever they get UTI [14] [17].

This study was therefore set to determine the efficacy of antimicrobial prophylaxis in preventing UTI among patients with CAKUT at a paediatric nephrology setting in South Africa.

\section{Materials and Methods}

The study was a retrospective review of the medical records of all patients be- 
tween 2 weeks and 18 years of age with documented congenital anomalies of the kidney and urinary tract being managed by the Division of Paediatric Nephrology, at CMJAH between January 2005 and December 2014. CMJAH is a large teaching hospital located in the City of Johannesburg, and attached to the University of the Witwatersrand. Its paediatric nephrology division provides a comprehensive tertiary and quaternary paediatric nephrology services primarily to children referred from Gauteng and its surrounding. The details of all patients cared for by the Division of Paediatric Nephrology of CMJAH are recorded in hard copy patient files which are kept in a secure filing room, located inside the division.

Permission was obtained from the Chief Executive Officer of CMJAH. Ethical approval for this study was obtained from the Human Research Ethics Committee and the Postgraduate Committee of the University of Witwatersrand before commencement of the study. Ethics Clearance number: M150709.

The total number of all the patients that attended the division between January 2005 and December 2014 were retrieved from the file data. Those that had CAKUT were selected. We went further to identify CAKUT patients that had at least one episode of UTI within the study period. These patients with UTI were divided into two groups; those that were placed on prophylactic antibiotics after the diagnosis of CAKUT was made and those that were not placed on any prophylactic antibiotics after the diagnosis of CAKUT was made. Finally, we compared the rate of UTIs between these two groups, over the study period.

During data collection, CAKUT was documented according to the exact diagnosis on the patients' files. It was later classified into anomalies of the kidney, anomalies of the collecting system, anomalies of the bladder, and Posterior Urethral Valves (PUV) as suggested by Song and Yosypiv [12]. The presence of a UTI was defined as finding significant bacteriuria with symptoms and signs of infection in the patient as charted in the files [17] [18] [19] [20].

Details on the microbiology of the UTIs of the study population and their complete sensitivity patterns was obtained by submission of an application to the Corporate Data Warehouse (CDW) of the National Health Laboratory Service (NHLS) requesting extraction of data from the Laboratory Information System (LIS) at the CMJAH NHLS laboratory. The application requested data on the organism type, and the susceptibility patterns of the UTIs diagnosed in the patients of our cohort.

After data collation and cleaning, analysis was done using Stata 13 statistical package [21]. A confidence interval of $95 \%$ was used, and for all analyses a p-value $<0.05$ was taken as statistically significant.

\section{Result}

Over the study period 691 new patients were seen at the clinic and, of those, 138 were diagnosed with CAKUT. Four records were excluded from analysis because they were lost to follow up after their diagnosis was made (they visited the clinic 
only once).

Of the remaining 134 patients there were 109 males and 25 females giving a male: female ratio of 4.4:1 (Table 1). The median age at presentation was 8.4 months (IQR 1.9 - 47.7) and the median duration of follow up was 39 months (IQR $=12.5-81.7)$.

Out of the 134 patients with CAKUT, 36 patients had been started on prophylactic antibiotics after the diagnosis of CAKUT was made. Figure 1 shows the types of CAKUT on prophylactic antibiotics. The frequency of prophylactic antibiotic usage was highest among patients with urethral anomalies (35\%).

Ninety-eight (98) patients were not commenced on any prophylactic antibiotic. Forty-nine (50.0\%) of those without prophylactic antibiotics had at least one episode of UTI on follow up, while only seven (19.4\%) of those on antibiotic prophylaxis developed a UTI. The association between UTI and prophylactic antibiotic use is shown in Table 2. There was a statistically significant association between the use of prophylactic antibiotics and the rate of UTI $(\mathrm{p}<0.001)$. Patients who were not on prophylactic antibiotics were five times more likely to have a UTI (OR $=5.21, \mathrm{P}=0.001,95 \%$ CI: 1.9906 - 13.6277).

A more detailed breakdown of the use of prophylactic antibiotic and the rate of UTI among the different classes and sub groups of CAKUT can be seen in Table 3. There was a decreased frequency of UTI in patients on antibiotic prophylaxis in all the different classes and sub groups of CAKUT.

Table 4 and Figure 2 show the effect of prophylactic antibiotics on the pattern of the bacteria isolated among the different types of CAKUT. Prophylactic

Table 1. Age at presentation and sex distribution of the study population.

\begin{tabular}{cccc}
\hline Age (months) & Males & Females & Total \\
$\mathbf{N}(\%)$ & N (\%) & $76)$ \\
\hline$<12$ & $61(56.0)$ & $15(60.0)$ & $30(22.4)$ \\
$12-59$ & $24(22.0)$ & $6(24.0)$ & $21(15.7)$ \\
$60-120$ & $21(19.3)$ & $0(0.0)$ & $7(5.2)$ \\
$>120$ & $3(2.8)$ & $4(16.0)$ & $134(100.0)$ \\
Total & $109(100)$ & $25(100.0)$ & \\
\hline
\end{tabular}

Table 2. Showing association between antibiotic prophylaxis and UTI.

\begin{tabular}{cccc}
\hline ANTIBIOTIC & \multicolumn{3}{c}{ UTI } \\
\hline PROPHYLAXIS & YES & NO & TOTAL \\
& $\mathbf{n}(\%)$ & $\mathbf{n}(\%)$ & $36(100.0)$ \\
YES & $7(19.4)$ & $29(80.6)$ & $98(100.0)$ \\
NO & $49(50.0)$ & $49(50.0)$ & $134(100.0)$ \\
TOTAL & $56(41.8)$ & $78(58.2)$ & \\
\hline
\end{tabular}

$\mathrm{p}<0.001$ 


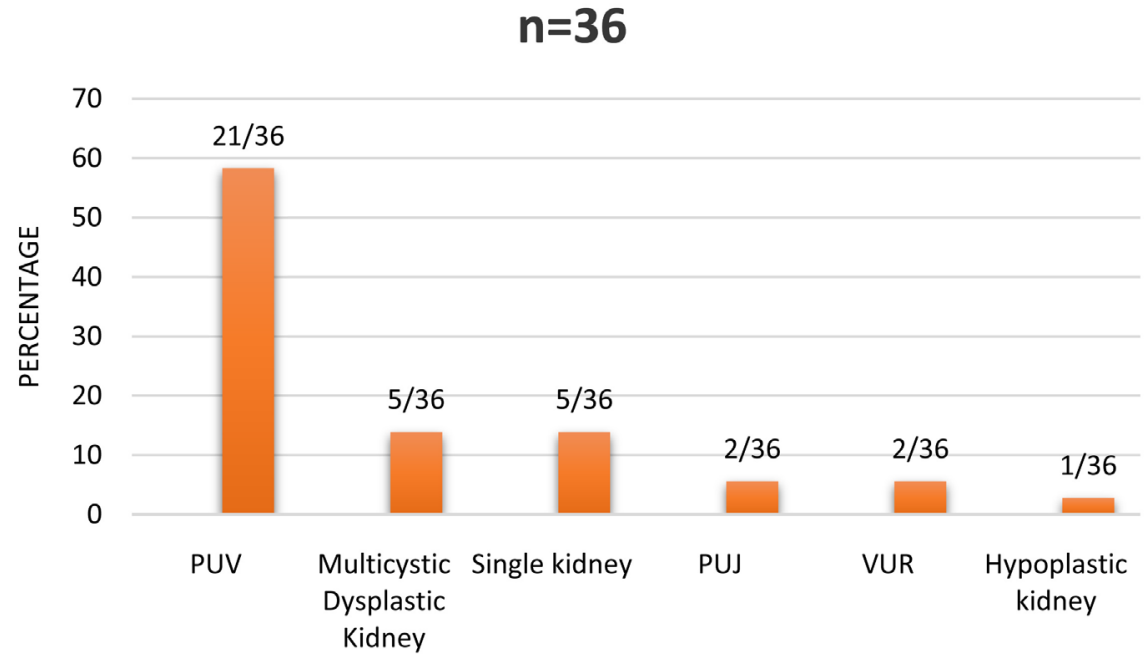

Figure 1. Showing the different types of CAKUT on antibiotic prophylaxis. PUJ = Pelviureteric Junction obstruction, PUV = Posterior Urethral Valves.

Table 3. A breakdown of the CAKUT subgroups, the use of antibiotic prophylaxis and the rate of UTI.

\begin{tabular}{ccc}
\hline & \multicolumn{2}{c}{ UTI } \\
\hline CAKUT & On Prophylaxis & No Prophylaxis \\
\hline Kidney $(\mathrm{n}=53)$ & $2 / 11$ & $10 / 42$ \\
Duplex $(\mathrm{n}=8)$ & 0 & $2 / 8$ \\
Single $(\mathrm{n}=18)$ & $2 / 5$ & $1 / 13$ \\
MCDK $(\mathrm{n}=19)$ & $0 / 5$ & $6 / 14$ \\
Others $(\mathrm{n}=8)$ & $0 / 1$ & $1 / 7$ \\
Collecting system (n=11) & $0 / 2$ & $6 / 9$ \\
PUJ $(\mathrm{n}=10)$ & $0 / 2$ & $6 / 8$ \\
VUJ $(\mathrm{n}=1)$ & 0 & $0 / 1$ \\
Bladder $(\mathrm{n}=10)$ & $0 / 2$ & $7 / 8$ \\
PBS $(\mathrm{n}=4)$ & 0 & $4 / 4$ \\
VUR $(\mathrm{n}=6)$ & $0 / 2$ & $3 / 4$ \\
Urethra $(\mathrm{n}=60)$ & $5 / 21$ & $26 / 39$ \\
PUV $(\mathrm{n}=60)$ & $5 / 21$ & $26 / 39$ \\
Total & $7 / 36$ & $49 / 98$ \\
\hline
\end{tabular}

Table 4. Showing the association between prophylactic antibiotics use and the bacteria isolated from the different types of CAKUT $(p=0.031)$.

\begin{tabular}{cccc}
\hline & Antibiotic & Prophylaxis & \\
\hline BACTERIA & YES & NO & TOTAL \\
& $\mathrm{n}(\%)$ & $\mathrm{n}(\%)$ & $\mathrm{n}(\%)$ \\
\hline E. COLI & $13(11.8)$ & $97(88.2)$ & $110(100.0)$ \\
\hline
\end{tabular}




\section{Continued}

\begin{tabular}{cccc}
\hline KLEBS & $19(26.4)$ & $53(73.6)$ & $72(100.0)$ \\
PSEUDO & $7(24.1)$ & $22(75.9)$ & $29(100.0)$ \\
ENTERO & $6(30.0)$ & $14(70.0)$ & $20(100.0)$ \\
ACINETO & $1(5.6)$ & $17(94.4)$ & $18(100.0)$ \\
OTHERS & $7(16.7)$ & $35(83.3)$ & $42(100.0)$ \\
TOTAL & $53(18.2)$ & $238(81.8)$ & $291(100.0)$ \\
\hline
\end{tabular}

E. coli $=$ Escherichia coli, Klebs $=$ Klebsiella pneumoniae, Pseudo $=$ Pseudomonas aeruginosa, Entero $=$ Enterobacter specie, Acineto = Acinetobacter baumanni.

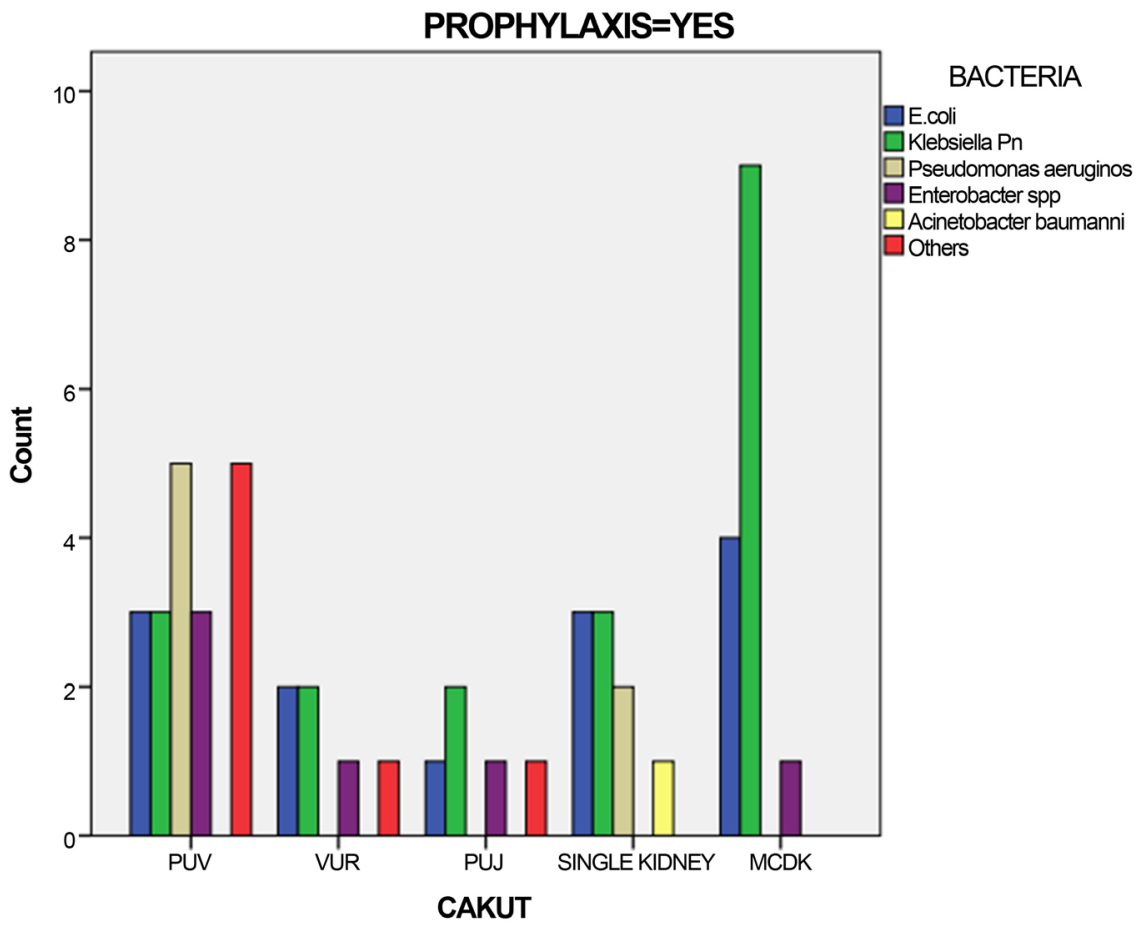

Figure 2. Showing the bacteria isolated from patients on prophylactic antibiotics.

antibiotics altered the pattern of bacteria isolated, with Klebsiella pneumoniae becoming the most common organism isolated rather than E. coli when compared to the group that were not on prophylactic antibiotics. There was a statistically significant association between the type of bacteria isolated and the use of antibiotic prophylaxis $(\mathrm{p}=0.031)$.

Figure 2 shows the bacteria isolated from patients on prophylactic antibiotics. There was a statistically significant association between the type of bacteria isolated and the use of antibiotic prophylaxis $(\mathrm{p}=0.031)$.

\section{Discussion}

Preventing recurrent UTIs in patients with CAKUT is one of the most effective ways of preventing progression to end stage kidney disease in this cohort of children [2] [8] [9] [10] but, due to conflicting reports on the benefits of antibi- 
otic prophylaxis in preventing UTI, the use of prophylactic antibiotics to prevent recurrent UTI/renal damage in children is still controversial [14] [17] [18] [22].

Brandstrom et al. agreed that antibiotic prophylaxis can protect against recurrent UTI and long-term sequelae in selected groups of patients [13] and other recent studies also advocate the use of prophylactic antibiotics to prevent recurrent UTI in infants with moderate to severe congenital hydronephrosis [9] [12].

Simoese et al. suggested a subgroup of patients that might benefit from antibiotic prophylaxis. These include those with obstructive uropathy until surgical intervention is achieved, the presence of severely dilated urinary tract, and grades III-V vesicoureteral reflux [22].

Craig et al. in Australia showed that low dose antibiotic prophylaxis decreased subsequent UTI episodes in children who had a previous UTI, and recent well-designed controlled trials have shown that some subgroups of children do benefit from antibiotic prophylaxis [8] [9] [13] [15] [23].

In our study population, the episodes of UTI were significantly decreased among our patients on antibiotic prophylaxis. Thirty-six (26.9\%) of the 134 patients with CAKUT were started on prophylactic antibiotics after the diagnosis of CAKUT was made and ninety-eight (73.1\%) were not commenced on any antibiotic. Over a follow up period of 39 months (IQR = $12.5-81.7), 7$ (19.4\%) of those on prophylactic antibiotics developed at least one UTI as compared to 49 $(50.0 \%)$ of those who were not on prophylaxis $(p=0.001)$. The odds for developing a UTI were increased 5fold among patients with CAKUT who were not on prophylactic antibiotics (OR $=5.21, \mathrm{p}=0.001,95 \% \mathrm{CI}: 1.9906$ - 13.6277).

Craig's study found that 55 (19\%) of 288 children without antibiotic prophylaxis developed UTI, while only 36 (13\%) of the 288 in the antibiotic group developed UTI (Hazard ratio in antibiotic group $=0.61 ; 95 \%$ CI: $0.40-0.93$ ) [16]. Also, in the RIVUR trial, antibiotic prophylaxis with trimethoprim/sulfamethoxazole decreased the risk of UTI recurrence by $50 \%$ among 607 children with VUR [15].

Again, Wang et al. [24] demonstrated that continuous antibiotics prophylaxis significantly reduced the risk of recurrent febrile or symptomatic UTI (OR = $0.63,95 \% \mathrm{CI}=0.42-0.96$ ) in children with VUR.

Our results emphasize the positive role that antibiotic prophylaxis can play in the prevention of UTI in children with CAKUT. Unfortunately, due to the retrospective nature of our data collection, we could not analyze the long-term effect of antibiotic prophylaxis on renal function but we feel that just to be able to prevent the morbidity of each UTI, it is worthwhile putting at least some children with CAKUT, as suggested by Simoese, on antibiotic prophylaxis.

Currently, the division of paediatric nephrology at CMJAH does not have any antibiotic prophylaxis protocol for the management of patients with UTI and/or CAKUT. Each index patient is treated based on his/her unique clinical condition. The results of this study will help us change this policy to place more patients onto antibiotic prophylaxis. 
As mentioned above, the extent to which antibiotic prophylaxis influenced the development of microbial resistance in this study was not explored other than to compare the group who had been on prophylaxis with the group who had not.

There was a statistically significant association between the type of bacteria isolated and the use of antibiotic prophylaxis $(\mathrm{p}=0.031)$. In the group who were on antibiotic prophylaxis, Klebsiella pneumoniae was the most common organism isolated as opposed to E. coli in the group that were not on prophylactic antibiotics.

Our study findings are in keeping with other reports which have showed that children on prophylactic antibiotics are often infected with causative organisms other than E. coli [25] [26].

It is recommended that the urine bacterial profile of CAKUT patients on prophylactic antibiotics are reviewed regularly [13] [27]. This will enable physicians to remain ahead of emerging strains of atypical organisms in this cohort of patients.

\section{Conclusion}

Antibiotic prophylaxis was very effective in decreasing the rate of UTI in our cohort of patients with CAKUT. Although we could not ascertain which particular subgroup of CAKUT would benefit most from prophylactic antibiotic use, it is worthwhile putting at least some children with CAKUT on antibiotic prophylaxis.

\section{Future Research}

1) To determine which of the conditions which make up CAKUT are most suitable for antibiotic prophylaxis.

2) To determine which antibiotics are most suitable for prophylaxis in these conditions.

3) To determine the long-term effects of antibiotic prophylaxis on renal function in children with CAKUT.

4) To study the long-term effects of antibiotic prophylaxis on UTI resistance patterns in children with CAKUT.

\section{Recommendation}

Majority of our patients that were on antibiotic prophylaxis were PUV patients. It is recommended that more of the other types of CAKUT be placed on antibiotic prophylaxis to evaluate the effect of the later on rate of UTI for individual CAKUT types.

\section{Authors' Contributions}

Okoronkwo N. C. conceived and designed the manuscript, helped in acquisition of data, analysis and interpretation of data, and also wrote the manuscript.

Mudi A. contributed in the design and revision of the manuscript, and gave 
final approval of the version to be published.

Levy C. helped with acquisition of data and interpretation of the analyzed data, edited the manuscript and gave final approval of the version to be published.

Khumalo T. helped with acquisition of data and interpretation of the analyzed data, and gave final approval of the version to be published.

Moonsamy G. helped with acquisition of data and interpretation of the analyzed data, and gave final approval of the version to be published.

\section{Acknowledgements}

The authors acknowledge all the nurses and staffs of the Paediatric Nephrology Division of CMJAH, especially Ms. Sophie, for their support during the data collection.

\section{Conflicts of Interest}

Cecil Levy has received speaker fees from Roche Pharmaceuticals. The other authors have nothing to declare.

\section{References}

[1] Schlager, T.A. (2001) Urinary Tract Infections in Children Younger than 5 Years of Age: Epidemiology, Diagnosis, Treatment, Outcomes and Prevention. Paediatric Drugs, 3, 219-227. https://doi.org/10.2165/00128072-200103030-00004

[2] Hamid, F., Islam, R., Paul, N., Nusrat, N. and Parveen, R. (2013) Urinary Tract Infection in Children: A Review. Delta Medical College Journal, 1, 51-57. https://doi.org/10.3329/dmcj.v1i2.15919

[3] Riskin, A., Toropine, A., Bader, D., Hemo, M., Srugo, I. and Kugelman, A. (2013) Is It Justified to Include Urine Cultures in Early ( $<72$ Hours) Neonatal Sepsis Evaluations of Term and Late Preterm Infants? American Journal of Perinatology, 30, 499.

[4] Quigley, R. (2009) Diagnosis of Urinary Tract Infection in Children. Current Opinion in Pediatrics, 21, 194-198. https://doi.org/10.1097/MOP.0b013e328326f702

[5] Alkhateeb, N.E., Al Azzawi, S. and Al Tawil, N.G. (2014) Association between UTI and Urinary Tract Abnormalities: A Case-Control Study in Erbil Ciy/Iraq. Journal of Pediatric Urology, 10, 1165-1169. https://doi.org/10.1016/j.jpurol.2014.05.006

[6] Twaij, M. (2000) Urinary Tract Infection in Children: A Review of Its Pathogenesis and Risk Factors. Perspectives in Public Health, 120, 220-226. https://doi.org/10.1177/146642400012000408

[7] Ring, E. and Zobel, G. (1988) Urinary Infection and Malformation of Urinary Tract in Infancy. Archives of Disease in Childhood, 63, 818-820. https://doi.org/10.1136/adc.63.7.818

[8] Merguerian, P.A., Sverrisson, E.F., Herz, D.B. and McQuiston, L.T. (2010) Urinary Tract Infections in Children: Recommendations for Antibiotic Prophylaxis and Evaluation. An Evidence-Based Approach. Current Urology Reports, 11, 98-108. https://doi.org/10.1007/s11934-010-0095-7

[9] Herz, D., Merguerian, P. and McQuiston, L. (2014) Continuous Antibiotic Prophylaxis Reduces the Risk of Febrile UTI in Children with Asymptomatic Antenatal Hydronephrosis with Either Ureteral Dilatation, High-Grade Vesicoureteral Reflux, or Ureterovesical Junction Obstruction. Journal of Pediatric Urology, 10, 650-654. 
https://doi.org/10.1016/j.jpurol.2014.06.009

[10] Masnata, G., Manca, V., Chia, L. and Esu, F. (2015) News on Pediatric Urology. Journal of Paediatric and Neonatal Individualized Medicine, 4, e040225.

[11] Zelikovic, I., Adeiman, R.D. and Nancarrow, P.A. (1992) Urinary Tract Infection in Children-An Update. Western Journal of Medicine, 157, 554-561.

[12] Greenfield, S.P. (2011) Antibiotic Prophylaxis in Pediatric Urology: An Update. Current Urology Reports, 12, 126-131. https://doi.org/10.1007/s11934-010-0164-y

[13] Brandstrom, P. and Hansson, S. (2015) Long-Term Low-Dose Prophylaxis against Urinary Tract Infections in Young Children. Pediatric Nephrology, 30, 425-432. https://doi.org/10.1007/s00467-014-2854-Z

[14] Robinson, J.L., Finlay, J.C., Lang, M.E. and Bortolussi, R. (2015) Canadian Paediatric Society, Community Paediatrics Committee, Infectious Diseases and Immunization Committee. Position Statement: Prophylactic Antibiotics for Children with Recurrent Urinary Tract Infections. Paediatrics and Child Health, 20, 45-47. https://doi.org/10.1093/pch/20.1.45

[15] Hoberman, A., et al. (2014) Antimicrobial Prophylaxis for Children with Vesicoureteral Reflux. The New England Journal of Medicine, 370, 2367-2376. https://doi.org/10.1056/NEJMoa1401811

[16] Craig, J.C., Simpson, J.M., Williams, G.J., Lowe, A., Reynold, G.J., McTaggart, S.J., et al. (2009) PRIVENT Investigators. Antibiotic Prophylaxis and Recurrent Urinary Tract Infection in Children. The New England Journal of Medicine, 361, 1748-1759. https://doi.org/10.1056/NEJMoa0902295

[17] American Academy of Pediatrics (2011) Urinary Tract Infection in Children: Clinical Practice Guideline for the Diagnosis and Management of the Initial UTI in Febrile Infants and Children 2 to 24 Months. Pediatrics, 128, 595. https://doi.org/10.1542/peds.2011-1330

[18] Song, R. and Yosypiv, I.V. (2011) Genetics of Congenital Anomalies of the Kidney and Urinary Tract. Pediatric Nephrology, 26, 353-364. https://doi.org/10.1007/s00467-010-1629-4

[19] White, B. (2011) Diagnosis and Treatment of Urinary Tract Infection in Children. American Family Physician, 83, 409-415.

[20] Hanson, S., Brandstrom, P., Jodal, U. and Larsson, P. (1998) Low Bacterial Counts in Infants with Urinary Tract Infection. The Journal of Pediatrics, 132, 180-182. https://doi.org/10.1016/S0022-3476(98)70512-8

[21] Papanastasiou, D., Dimitracopoulos, G., Drakou, A., Haliotis, F. and Spiliopoulou, I. (1998) Significant Bacteriuria in Infants and Young Children and Relation to Bacterial Species and Pyuria. Clinical Microbiology and Infection, 4, 284-287. https://doi.org/10.1111/j.1469-0691.1998.tb00058.x

[22] Simoese Silva, A.C. and Oliveira, E.A. (2015) Update on the Approach of Urinary Tract Infection in Childhood. The Journal of Pediatrics, 91, S2-S10. https://doi.org/10.1016/j.jped.2015.05.003

[23] Brandstrom, P., Jodal, U., Sillen, U. and Hansson, S. (2011) The Swedish Reflux Trial; Review of a Randomized Controlled Trial in Children with Dilating Vesicouretral Reflux. Journal of Pediatric Urology, 7, 594-600. https://doi.org/10.1016/j.jpurol.2011.05.006

[24] Wang, H.-H.S., Gbadegesin, R.A., Foreman, J.W., Nagaraj, S.K., Wigfall, D.R., Wiener, J.S., et al. (2015) Efficacy of Antibiotic Prophylaxis in Children with Vesicoureteral Reflux: Systematic Review and Meta-Analysis. The Journal of Urology, 
193, 963-969. https://doi.org/10.1016/j.juro.2014.08.112

[25] Saadeh, S.A. and Mattoo, T.K. (2011) Managing Urinary Tract Infections. Pediatric Nephrology, 26, 1967-1976. https://doi.org/10.1007/s00467-011-1801-5

[26] Lutter, S.A., Currie, M.L., Mitz, L.B. and Greenbaum, L.A. (2005) Antibiotic Resistance Patterns in Children Hospitalized for Urinary Tract Infection. Archives of Pediatrics and Adolescent Medicine, 159, 924-928.

https://doi.org/10.1001/archpedi.159.10.924

[27] National Institute for Health and Clinical Excellence (NICE) (2007) Guidelines 54. Urinary Tract Infection in Children: Diagnosis, Treatment and Long-Term Management. 